\title{
MRSBulletin Opening a new page
}

\section{Quo vadis?}

T The month of April saw a major transition at the Materials Research Society headquarters on the publications side. Elizabeth (Betsy) Fleischer completed two decades as editor of MRS Bulletin and became MRS Principal Development Editor. Tim Palucka joined MRS as Science News Editor. I transitioned to the editorship of MRS Bulletin after being MRS Web Science Editor for over a decade. The three of us now form a science team at MRS to assimilate, filter, and disseminate materials science news and content through various outlets, in partnership with Cambridge University Press. Our goals reflect the mission of MRS to address global problems through materials research solutions and to improve the quality of life.

It is a privilege and an honor to be named editor of $M R S$ Bulletin, as well as a tremendous responsibility. The Bulletin occupies an important position within the materials research community. Betsy Fleischer has more than ably accomplished this during her tenure as editor. She has guided the publication through numerous changes culminating in its current standing in the science community as a world-class, high-quality, scientific publication. She has pushed content in multiple directions, such as the April 2008 special and expanded issue on "Harnessing Materials for Energy," the ongoing ENERGY QuARTERly feature, the "Materials Challenges for the Next Century" series marking the millennium, and an upcoming special issue on Sustainability.

Says V.S. Arunachalam, who worked closely with Betsy Fleischer on the special energy issue as well as other content, "Betsy saw challenges in materials research and development at two different planes. One, as a true scientist focusing on the research front at the cutting edge. Second, she saw the role and impact of materials in our society and wanted to chronicle it. It is on this plane that she ventured quite far, and I was privileged to be associated with her here, articulating on materials challenges in the 21 st century, talking and interviewing people who make a difference to the world of materials. For her, the entire materials supply chain is a veritable delight to be explored at every facet." The good news here is that Betsy Fleischer will continue to be involved with MRS Bulletin and continue in its evolution as part of the MRS HQ science team.
Quo vadis, MRS Bulletin? Materials research continues to evolve and expand in directions that could not have been conceived even a decade ago. The explosion of research in nanoscience and nanotechnology, collaborative work between biological and medical researchers with materials scientists, advances in characterization techniques, atom-level imagingall of these are important to solve scientific, technological, and, ultimately, societal problems. MRS Bulletin has been at the forefront of overviewing slices from these areas in neatly packaged theme issues. With the help of our dedicated volunteers, we will continue to cover major materials research areas through themes and articles, as well as information essential to our readership through the various departments, using world-class editorial standards. Each MRS Bulletin theme represents a group of colleagues in a specific field communicating their work to us.

MRS Bulletin is not and cannot be published in isolation. The Bulletin Editorial Board, very adeptly led by Paul Drzaic, our volume organizers, guest editors, authors, and other volunteers, work together to guide the development of content, ensuring relevance, quality, and balance. I look forward to working closely with them.

I look forward to working with the dedicated and talented MRS Bulletin editorial staff, including Managing Editor Judy Meiksin, Technical Editor Lori Wilson, and Editorial Assistant Ben Moriarty. Their roles in the publication of the Bulletin are vital, and I am confident that we have an outstanding team. I also look forward to working with the rest of the MRS staff at headquarters, all of whom play important roles in the publication of the Bulletin.

I invite you to contact me or the editorial staff with ideas for theme topics, single articles, and other features for $M R S$ Bulletin. Keep us informed of research breakthroughs and advances. I look forward to hearing from the world-wide materials community about how the Bulletin could better serve your needs and the needs of the community as we continue our quest to improve the quality of life through materials solutions. 